\section{The Habitat-Trees experiment: using exotic tree species as new microhabitats for the native fauna}

\author{
Livia Zapponi ${ }^{(1-2)}$, Emma Minari ${ }^{(1)}$, Luca Longo ${ }^{(3)}$, Ilaria Toni ${ }^{(1)}$, Franco \\ Mason $^{(4)}$, Alessandro Campanaro ${ }^{(1-5)}$
}

The cavities that develop in veteran trees represent a key microhabitat for forest biodiversity and especially for secondary cavity nesters that rely on this resource for shelter. Since the availability of deadwood, veteran and hollow trees is threatened by forest management, we explored the possibility of increasing the presence of these scarce resources. To increase the abundance of dead wood-microhabitats, 113 trees of the hybrid planes (Platanus $x$ acerifolia) were converted into new living structures, the Habitat Trees (HT). To investigate the potential of this resource on the native avian fauna, six types of cavities were designed according to the size requirements of the target bird species. The temporal evolution of the cavities and their use by birds were then studied for eight years. The artificial cavities generally did not compromise growth and stability of the trees, and the majority remained alive. These hollows offered better thermal insulation compared to traditional nest-boxes and natural cavities. Their use increased during the first three years, reaching the $80 \%$. In the following years, the use declined (probably because of the increase of rot and displacement of the lids). This highlights the need of management to maintain their suitability through time. Our results suggest a possible cost-effective alternative use of alien tree species, which should be included in management actions to compensate the shortage of hollow trees in managed forests.

Keywords: Birds, Deadwood, Exotic Species, Forest Management, LIFE Project, Saproxylic Organisms

\section{Introduction}

Old and dead trees are the main source of natural cavities and hollows used as shelter by many species of vertebrates (Gibbons \& Lindenmayer 2002) and invertebrates (Müller et al. 2013). For the majority of these species, tree hollows represent an irreplaceable microhabitat (Gibbons \& Lindenmayer 2002). Obligate hollow nesters have been estimated to be as much as $5 \%$ of the European and North American birds, most belonging Strigiformes (Newton 1994). Most of these species are secondary cavity nesters, i.e., relying on the presence of cavities created by other birds, insects or wood decay processes. The availability of cavities limits the population size of such species, as proved by the experimental addition and removal of nestboxes (Dhondt 2012). The nest site limitation has been generally observed in humanlandscapes, but forest type and age, as well to the orders Passeriformes, Piciformes and

$\square$ (1) Centro Nazionale per lo Studio e Conservazione della Biodiversità Forestale "Bosco Fontana", str. Mantova 29, I-46045 Marmirolo (MN, Italy); (2) Consiglio Nazionale delle Ricerche, Istituto di Biologia Agroambientale e Forestale, v. Salaria Km 29.300, I-00015 Monterotondo Scalo (RM, Italy); (3) v. XXVIII Marzo 19, I-37133 Verona (Italy); (4) Centro Nazionale per lo Studio e la Conservazione della Biodiversità Forestale "Bosco Fontana" di Verona, v. C. Ederle 16/a I-37126 Verona (Italy); (5) Dipartimento di Biologia e Biotecnologie “Charles Darwin”, Università “La Sapienza”, Roma (Italy)

@ Alessandro Campanaro (ale.naro@gmail.com)

Received: Mar 06, 2014 - Accepted: Jul 06, 2014

Citation: Zapponi L, Minari E, Longo L, Toni I, Mason F, Campanaro A, 2014. The HabitatTrees experiment: using exotic tree species as new microhabitats for the native fauna. iForest 8: 464-470 [online 2014-10-22] URL: http://www.sisef.it/iforest/contents/? id=ifor $1281-007$

Communicated by: Massimo Faccoli

as community complexity, can contribute to the shortage of these microhabitats (Cornelius et al. 2008). Also, the presence of microhabitat-bearing trees represents a crucial factor for the diversity and abundance of saproxylic beetles (Bouget et al. 2014a).

The availability of microhabitats on living trees is often reduced by current silvicultural practices, since thinning usually removes trees more prone to exhibit or develop hollows (Larrieu et al. 2012). The rarity of these key resources offered by old and hollow trees is increasing in Europe, threatening the conservation of associated organisms (Sebek et al. 2013). Considering the long timespan taken for such cavities to naturally develop, conservation planners should act to halt hollow scarcity (Manning et al. 2013).

The European LIFE project 1999-2003 "Bosco della Fontana: urgent conservation actions on a relict habitat" (NAT/IT/99/006 245 - Cavalli \& Mason 2003) represented a thorough exploration of the potentialities of artificial deadwood management. The project was aimed at preserving Bosco Fontana - one of the last remaining floodplain forest habitat in the Po basin (northern Italy) - and its stock of deadwood, aging trees and saproxylic fauna (sensu Speight 1989). Former studies on its forest dynamics performed in 1995 (Mason 2004) reported that alien tree species present in the site (the hybrid plane Platanus $x$ acerifolia and the red oak Quercus rubra) were highly invasive and represented a threat to the local flora, especially to the pedunculate oak Quercus robur. Such exotic species were planted in the 1950's to offset the intense harvest occurred in the II World War, as well as the storm that in 1949 felled more than 2000 trees in the SW part of Bosco Fontana.

The main objective of the present study were the management of the alien species $P$. $x$ acerifolia present at Bosco Fontana to: (i) create microhabitats for bird nesting, and (ii) induce wood decay to increase the amount of available deadwood. These two goals were accomplished through the creation of Habitat Trees (hereafter HT), i.e., living trees with hollows for cavity-nesting birds and deep pockets cut in the lower part of the trunk for water accumulation. The overall objective of the study was to assess whether these artificial microhabitats were used by the target species. Specifically, we assessed the use of cavities by different bird species in the short and medium term, and the thermal insulation offered by these artificial cavities. We also monitored the evolution of such cavities to verify their suitability to wildlife and their effect on the stability of trees through time. Finally, we critically analyzed the results of the experiment 10 years later to provide general recommendations to forest managers. 


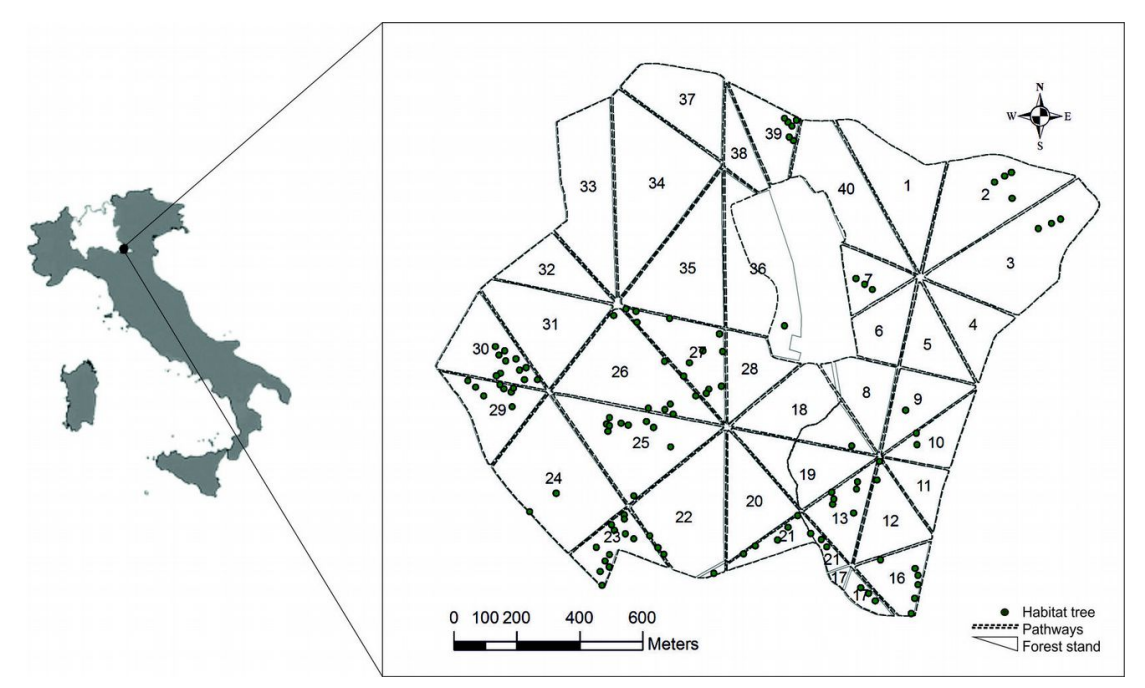

Fig. 1 - Location of the study area, the Bosco Fontana Natural State Reserve, showing the subdivision of forest into sections and the distribution of the Habitat Trees.

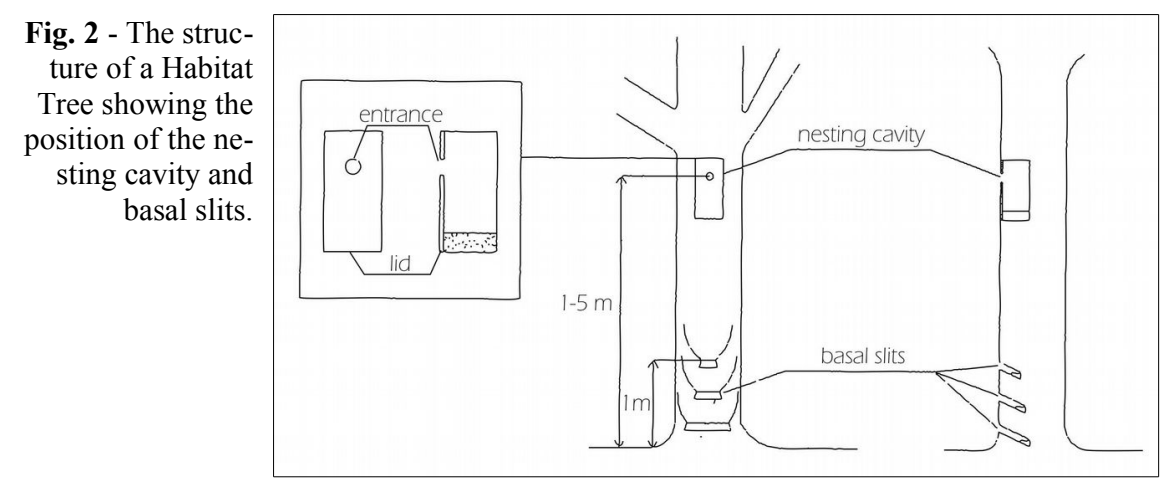

\section{Materials and Methods}

Study area

The Bosco Fontana State Natural Reserve is located in northern Italy $\left(45^{\circ} 12^{\prime} 04.93^{\prime \prime}\right.$ $\mathrm{N}, 10^{\circ} 44^{\prime} 33.54^{\prime \prime} \mathrm{E}$, mean elevation $36 \mathrm{~m}$ Fig. 1) and covers 236 ha. It is a Nature 2000 site (IT20B0011) and part of the European LTER Network (http://www.lter-europe.net/). Eighty-five percent of the reserve is covered by an ancient plain forest and a semi-natural woodland (Mason 2004) belonging to the Sub-Atlantic and medio-European oak or oak-hornbeam forests of the Carpinion betuli (code 9160 - Habitats Directive - 1992/43/CEE). Most abundant spe-

Tab. 1 - Description of the different types of cavities created.

\begin{tabular}{lcccccc}
\hline \multirow{2}{*}{ Target bird species } & \multirow{2}{*}{$\begin{array}{c}\text { Cavity } \\
\text { type }\end{array}$} & \multirow{2}{*}{$\begin{array}{c}\text { No. of } \\
\text { cavities } \\
\text { created }\end{array}$} & \multirow{2}{*}{$\begin{array}{c}\text { Entrance } \\
\left.\text { area } \mathbf{( c m}^{2}\right)\end{array}$} & \multicolumn{2}{c}{ Cavity size (cm) } \\
\cline { 5 - 7 } & & & & Height & Width & Depth \\
\hline Parus palustris, P. caeruleus & $\mathrm{A}$ & 28 & 21.2 & 25 & 12 & 12 \\
Parus major, Passer montanus & $\mathrm{B}$ & 54 & 32.2 & 25 & 12 & 12 \\
Jynx torquilla, Sitta europaea & $\mathrm{C}$ & 10 & 45.4 & 40 & 12 & 12 \\
Muscicapa striata & $\mathrm{D}$ & 5 & 55.0 & 25 & 14 & 15 \\
Athene noctua & $\mathrm{E}$ & 7 & 153.9 & 40 & 18 & 18 \\
Strix aluco & $\mathrm{F}$ & 8 & 441.0 & 80 & 24 & 21 \\
\hline
\end{tabular}

\section{Sample selection and microhabitat} creation

HT were created between 2000 and 2002 using 112 exotic $P$. x acerifolia trees with diameter at breast height (DBH) of 40-75 $\mathrm{cm}$. The distribution of the selected HT was dependent on the availability of such species on the ground (Dalponte et al. 2007), taking care of choosing trees at least $20 \mathrm{~m}$ apart. Each tree was then subjected to two interventions aimed at creating 2-3 basal pockets and a nesting cavity (Fig. 2). Basal pockets were created with specific cuts at the base of the trunk to trigger a process of rot through the temporary accumulation of water, thus favoring the colonization of water-dependent fauna. Basal pockets were created as vertical incisions made using a chain saw. The sizes of the slits were chosen according to the trunk diameter, with their width decreasing upwards, i.e., with larger pockets at the bottom. As for the nesting cavities, they were created to resemble the hollows that generally characterize older trees, providing foraging resources and shelter to wildlife (Gibbons \& Lindenmayer 2002), especially to secondary cavity nesters (Martin et al. 2004). Nesting cavities were created 1-4 m above the ground by cutting and extracting a wood block from the tree, then a thin slice was cut to make a lid to close the artificial hollow. The lid was attached to the cavity with grafting mastic and finally an entrance hole was bored, with a size diameter chosen according to the target species. Further technical details and costs are reported by Cavalli \& Mason (2003). Cavities were of 6 different sizes (type A to F - Tab. 1), according to the bird target species: type A for marsh tit Parus palustris and blue tit $P$. caeruleus; type B for great tit $P$. major and tree sparrow Passer montanus; type C for wryneck Jynx torquilla and nuthatch Sitta europaea; type $\mathrm{D}$ for spotted flycatcher Muscicapa striata; type E for little owl Athene noctua, and finally, type F for tawny owl Strix aluco. The type of cavity created was depending on the diameter of the bearing tree, with larger individuals hosting bigger cavities.

\section{Monitoring the HT performance and evolution}

Surveys were periodically carried out to assess the performance of HTs in term of conditions of the cavities, their thermal insulation and physical and structural conditions of the hosting trees. Seven data loggers (Testostor 179) were positioned inside and outside the artificial cavities, within a nest of the primary hole nester Dendrocopos major, and two cement nest-boxes for Parus sp. Data loggers recorded the temperature every 30 minutes, from March to September 2001. DBH of each tree was measured to evaluate the effect of the interventions on tree growth. Position (standing, fallen) and structure 

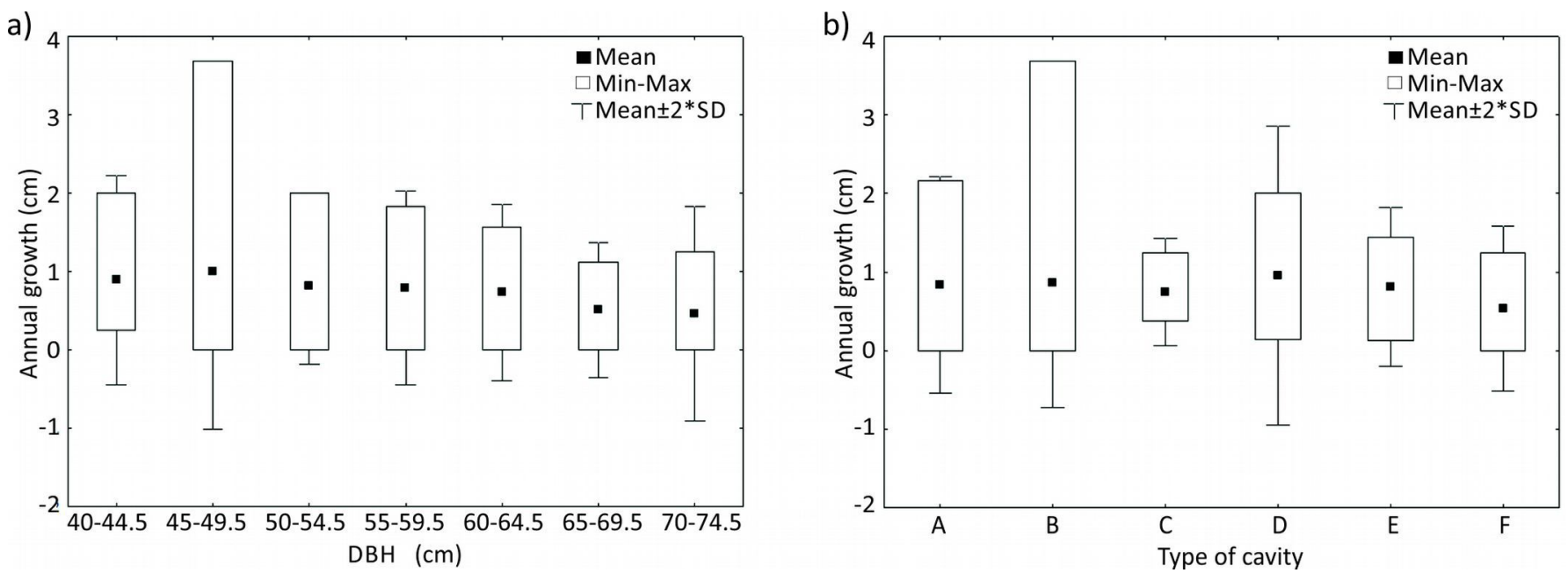

Fig. 3 - Boxplot of mean annual growth of trees according to DBH class before the intervention (a) and type of nesting cavity (b). For the de scription of the different types of cavities, see Tab. 1.

(e.g., snag) of trees died after the creation of cavities was recorded. Cavity conditions were evaluated by focusing on the lid, to assess whether tree growth had compromised its original position and/or caused the closure of the entrance hole.

\section{Evaluation of HT use}

Assessment of the HT use by birds took place at the end of the breeding season, the most suitable period according to Longo (2003a). Cavities were visually inspected with a mirror to assess whether: (1) the cavities were in good conditions, (2) if there was direct evidence of occupancy by one of the target species, and (3) if there were indirect clues of nesting, such as feather rests, unhatched and broken eggs, dead nestling and droppings (Longo 2003a). The first survey was carried out in 2002 (Longo 2003a, $2003 \mathrm{~b}$ ), whereas the second survey was conducted in 2008. A third survey focused only on $S$. aluco nests was performed in 2010 (Maffezzoli \& Martignoni 2010).

\section{Statistical analysis}

The effect of the different treatments, i.e., cavity types, and DBH classes on annual trees' growth and on the status of the lids and entrances were tested with Monte Carlo (30 000 iterations) non-parametric ANOVA and Chi-square test using the software package EcoSIm 7.71 (Gotelli \& Entsminger 2001). Logistic regression models were used to investigate the influence of HT distance from forest tracks and the probability of use, using presence-absence data of the target species (R 3.0, The R Foundation for Statistical Computing 2013).

\section{Results}

\section{HT evolution}

Seventy-seven percent of HTs were still alive eight years after their set up $(\mathrm{n}=87)$. Neither the different treatments nor the age class significantly affected trees' growth (Fig. 3). As for the artificial nests, the type of cavity did not affect the sealing of the entrance hole (Fig. 4a). However, this was influenced by the size class of trees $\left(\mathrm{H}_{[6,82]}\right.$ $=15.58, \mathrm{p}=0.02$ ), with trees sized $45-55 \mathrm{~cm}$ being more prone than others to seal the hole (Fig. 4b). The inclusion of the lids was more frequent for types $\mathrm{F}$ and $\mathrm{B}$, whereas the expulsion occurred only for a type $\mathrm{C}$ cavity (Fig. 4c). The most frequent cause of tree death was the breakage of the trunk, although both standing and fallen dead trees were found, with no significant differences between the latter two. Eight years after the beginning of the experiment, $18 \%$ of the trees with artificial nests became a snag, with no significant differences among nest types (Fig. 4d). Attacks by insects and fungi was found on $37 \%$ of the dead trees.
Fig. 4 - Evolution of artificial a) cavities 8 years after their creation (2000-2008): (a) number of HT with an open or closed entrance according to the age class; (b) number of HT with an open or closed entrance according to the type of cavity; (c) condition of the lid according the type of cavity; (d) number of HT c) still alive and snags for each

type of cavity. For the description of different types of cavities, see Tab. 1.
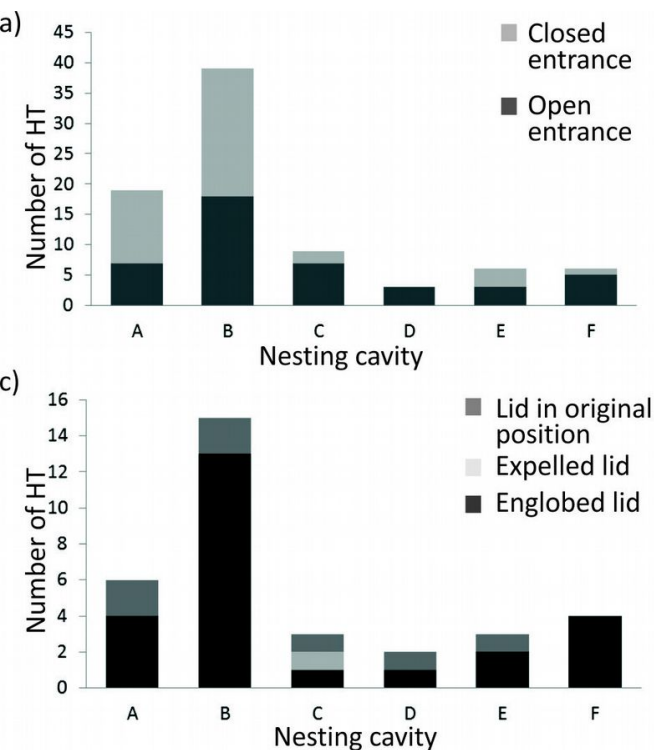
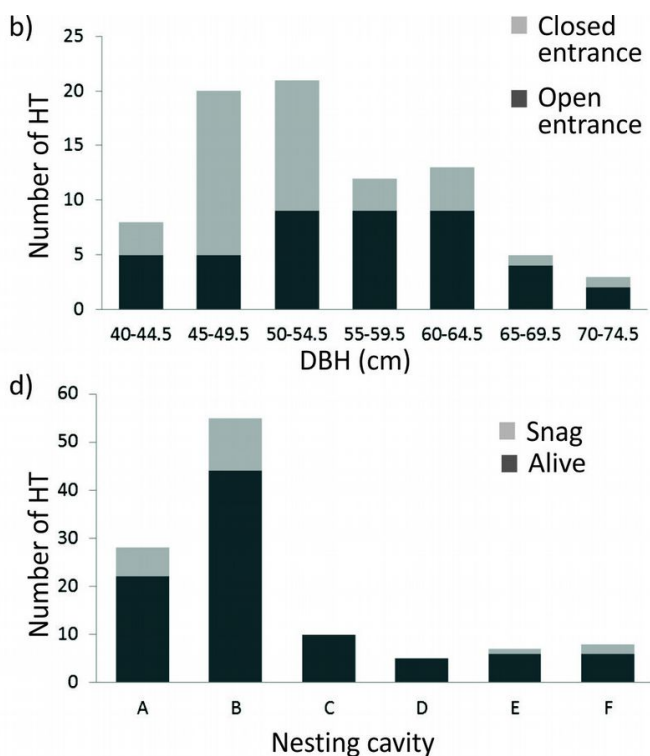
Fig. 5 - Temperature range inside cavities from March to

September 2001 (monthly maximum and minimum). The series was recorded inside a Dendrocopos major nest (DM); outside an artificial cavity for Strix aluco (Out); inside an artificial cavity for Strix aluco $(\mathrm{F})$; inside an artificial cavity for Parus major (B) and inside a wooden nest-box for Parus sp. (NB).

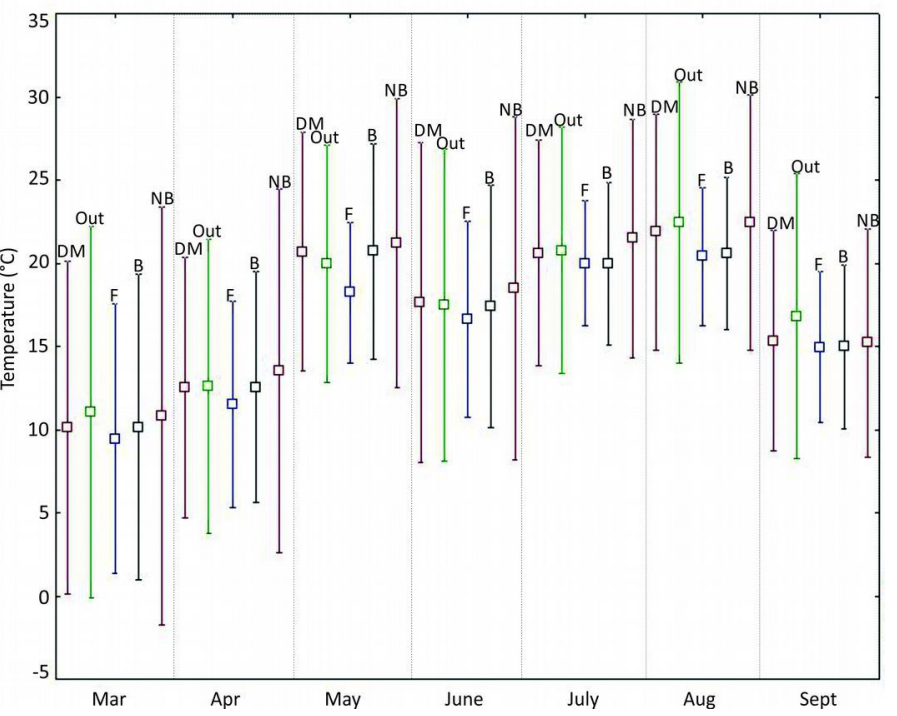

Comparing thermal insulation offered by the different structures (Fig. 5), the artificial cavities of HTs showed the lowest variation from March to September 2001, hence, the better insulation. Best thermal conditions were observed for the cavity built for $S$. aluco, with temperatures significantly more constant than those recorded outside the nest $(\mathrm{p}=0.001)$. These artificial cavities also showed a variation in temperature even lower as compared with the natural nest of Dendrocopos major. Conversely, data loggers inside the cement nest-boxes recorded the highest variation in temperature, i.e., an inner range of temperatures wider than outside.

\section{HT use}

Six of the nine target species where recorded in the HTs: P. caeruleus, P. major, S. europaea, M. striata and $S$. aluco, occupying altogether $80 \%$ of the cavities $(\mathrm{n}=87)$. Instead, no nests of $P$. palustris, $P$. montanus, J. torquilla and A. noctua were found, although such species are known to occur in the study area. The colonization rate of cavities significantly increased with time for $P$. major and $P$. caeruleus $\left(\chi^{2}=9.449, \mathrm{~d} f=2\right.$, $\mathrm{p}=0.002)$, and the two species also inhabited cavities not specifically created for them (Fig. 6). Similarly, both $S$. europaea and $M$. striata were found in nests created for other species (B-C and E, respectively). The DBH class of HTs did not significantly influence the use of the artificial nest. The probability of nests' use was instead significantly influenced by their distance from the forest edge, but only for $S$. aluco $\left(\chi^{2}=5.178, \mathrm{df}=1, \mathrm{p}=\right.$ 0.02 - Fig. 7).

\section{Discussion}

Although the creation of pockets and nests in the trunk may represent an invasive procedure affecting tree stability, vitality and
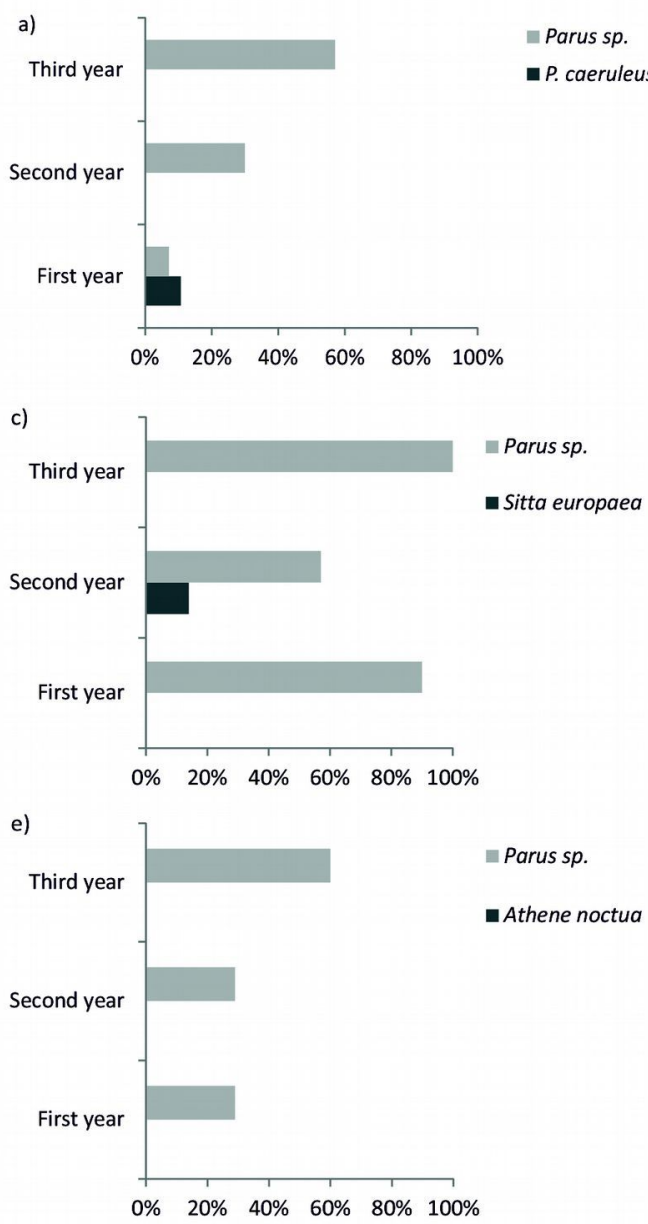

- Parus sp.

Athene noctua

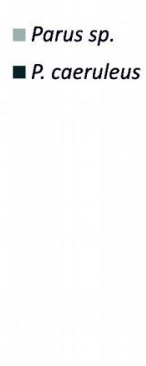

b)
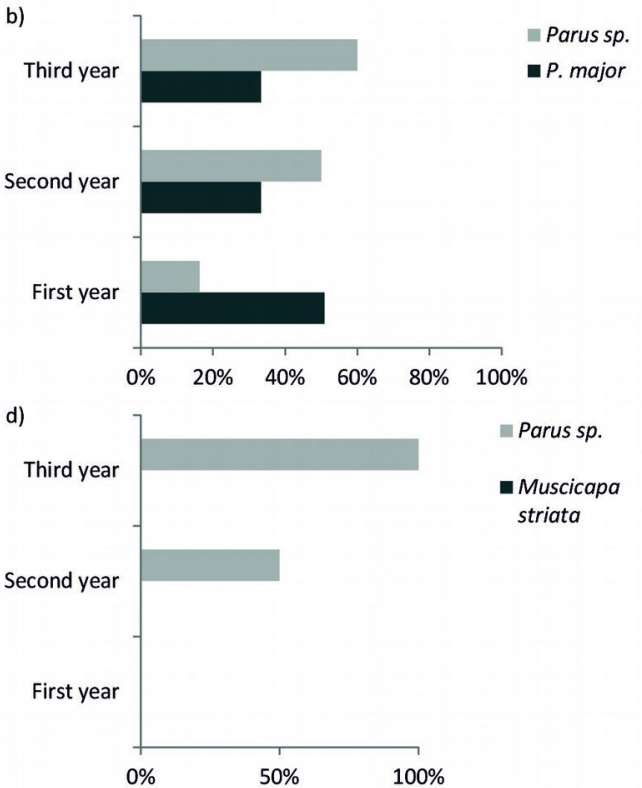

f)

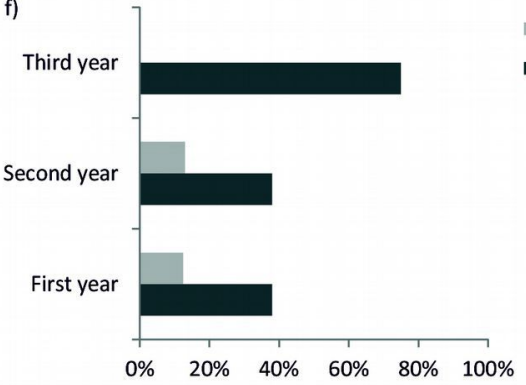

Fig. 6 - Use of the artificial cavities during the first three years after their creation (2001-2003), the different target species and the occurrence of the most dominant species (Parus sp.) for each type of cavity considered. See Tab. 1 for the description of cavities. 
Fig. 7 - Relationship between distance of the habitat tree from the forest edge and tawny owl (Strix aluco) presence.

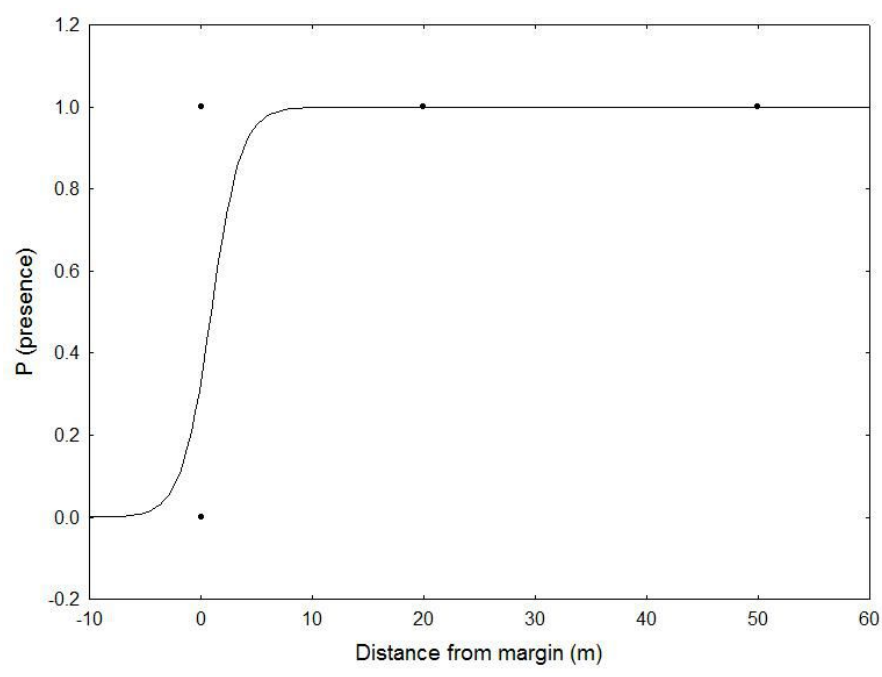

growth, the majority of the trees were still alive eight years later. Localized interventions on trunks did not substantially alter tree vitality, allowing their survival for several years. Less than $20 \%$ of trees broke and became a snag, and even if the creation of artificial cavities and pockets may have contributed to lessen their stability, trunk breakage occurred independently from tree diameter and the size of artificial holes. $\mathrm{Ca}$ vities surrounded by thick callous were used by neither target nor non-target species. According to the small tree reaction, HT may represent a resource available through time, if appropriately managed. Furthermore, cavities bored in HTs were better protected against extreme temperatures compared with traditional nest-boxes, providing a more favorable microclimate to nestings (GarciaNavas et al. 2008). Since the operational costs of traditional nest boxes and HT are comparable (Cavalli \& Mason 2003), we highly recommend the use of exotic tree species as HT. The frequency of colonization of the cavities by bird species agreed with the species abundance of Bosco Fontana observed in previous studies (Longo 2001, Maffezzoli \& Martignoni 2010). P. caeruleus and P. major were often found in nests created for larger species, showing a lack of specialization in terms of cavity size and entrance diameter, characteristic shared with other species as well (e.g., M. striata and $J$. torquilla). In contrast with what was observed by Charter et al. (2013), Parus sp. were able to breed in nests with wider entrances even in the presence of larger-sized competitors, possibly because the abundance of the latter was too low to generate interspecific competition (Robles et al. 2012). The occurrence of other secondary-hole nesters (e.g., J. torquilla) was more scarce, possibly due to their low plasticity in terms of nest-site and social structure (Zingg et al. 2010, Robles et al. 2012). Behavioral constraints represent a possible explanation for the lack of records referring to A. noctua (Tomé et al. 2008). Passerines are known to select for cavities in living trees (Robles et al. 2011), and thermoregulatory advantages are a likely cause of this selection (Remm et al. 2006). However, cavities were not used for long periods, possibly because of the frequent displacement of the plugs that delimited the entrance, increasing the risk of predation (Charter et al. 2010). Furthermore, the enlargement of the entrance was often associated with the soaking of the nest, another factor decreasing the cavity suitability (Wesolowski et al. 2002). Finally, the age of Bosco Fontana forest and its management favored the retention of old trees and high levels of deadwood, with an average of $64.26 \pm 51.69 \mathrm{~m}^{3} \mathrm{ha}^{-1}$ of downed deadwood (Travaglini et al. 2007). Considering that the average amount of deadwood in the European forests is $12.27 \mathrm{~m}^{3} \mathrm{ha}^{-1}$ (MCPFE 2007), it may be hypothesized that the high availability of natural cavities in our study site might exceed the demand. This highlights the relevance of other environmental factors in determining species' densities (Aitken \& Martin 2007, Remm et al. 2006), such as intraspecific interactions (Loukola et al. 2012). The experiment carried out at Bosco Fontana demonstrates that the use of alien species as HT could be applied to increase forest biodiversity. We suggest to perform these types of interventions on broadleaved species only. Following the results obtained in this project, the third Interreg project between Italy and Slovenia (Conosci il Carso) involved the creation of HT using Austrian pine (Pinus nigra). However, P. nigra has proven to be unsuitable to the above purposes because resin pouring from the cuts performed on living trees compromised the suitability of the cavities for birds (Filacorda, pers. comm.). A further experiment on conifers was performed during the LIFE04NAT/IT/000190 project "Conservation actions in Natura 2000". The slope of the site allowed only the creation of basal slits, due to the operational constraints. As reported in a 10 -years study by Lindenmayer et al. (2009), nest boxes are more successfully occupied in young forests where old hollow trees are missing. Moreover, nest boxes showed a short "effective occupancy time" (2-3 years only) because of the invertebrate infestation and competition for space (Lindenmayer et al. 2009). This short time usage was shared by HTs as well, and was probably influenced by the increasing presence of rot within the cavities. A further issue related with time was the lid displacement from artificial cavity, a frequent reaction due to tree growth. In this respect, a periodic maintenance of cavities in the winter should be performed in order to keep the cavities open, clean and suitable to the target species, enhancing their effectiveness. The maintenance should also guarantee the original position of the plug or its replacement when the entrance shape has changed (e.g., callus growth, enlargement due to predation attempt). These periodical checks should be more frequent on younger trees, since their faster growth tends to compromise the accessibility of the cavities. To facilitate cavity inspection, we suggest the use of plugs that can be opened. This would also allow additional studies to be carried out, such as those entailing the ringing of nestlings (Longo 2003a).

Mechanical damage occurred during cavity creation may trigger stress-induced flowering and fruiting that could hamper the removal of exotic species (Takeno 2012). Therefore, we recommend to carefully consider the species' physiology before planning the interventions, and choosing those seasons when trees are less reacting. When planning the HT position within the forest, security issues should be also considered. Since they could evolve in snags, we suggest to locate HTs at a safe distance from forest tracks or pedestrian paths. This approach should also favor bird colonization according to the reduced anthropic disturbance (Maffezzoli \& Martignoni 2010).

\section{Conclusions}

Forestry has nowadays to face the challenge of finding new instruments to achieve sustainable management without compromising the productivity (Levers et al. 2014). In this regard, we believe that the increase of hollow trees in forested areas should be a general prescription. The increase of microhabitats could be obtained combining two approaches: the creation of HT to increase the availability in the short term, and the release of trees to indefinite aging to ensure the natural creation of hollows in the long-term perspective. The active creation of microhabitat could compensate the time-lag needed for the self-restoration of old-growth features 
(Bouget et al. 2014b).

In conclusion, this study highlights the advantages and cost-effectiveness of increasing deadwood and microhabitat availability using alien plant species. These findings may be useful to contrast the detrimental effects of the decline of hollow-bearing trees.

\section{Acknowledgments}

The creation of the HTs was funded by the LIFE project NAT/IT/99/006245. We are grateful to M. Del Bianco for helpful discussion. We would like to thank A. Scudo and C. Morganti for their help during the HT monitoring. We greatly benefited from the comments of three anonymous reviewers on an earlier versionof the manuscript. Finally, we are also grateful to S. Hardersen and R.L. Rollins for language revision.

\section{References}

Aitken KH, Martin K (2007). The importance of excavators in hole-nesting communities: availability and use of natural tree holes in old mixed forests of western Canada. Journal of Ornithology 148: 425-434. - doi: 10.1007/s10336-0070166-9

Bouget C, Larrieu L, Brin A (2014a). Key features for saproxylic beetle diversity derived from rapid habitat assessment in temperate forests. Ecological Indicators 36: 656-664. - doi: 10.1016/j.ecolind.2013.09.031

Bouget C, Parmain G, Gilg O, Noblecourt T, Nusillard B, Paillet Y, Pernot C, Larrieu L, Gosselin F (2014b). Does a set-aside conservation strategy help the restoration of old-growth forest attributes and recolonization by saproxylic beetles? Animal Conservation 17 (4): 342-353. - doi: 10.1111/acv.12101

Cavalli R, Mason F (2003). Techniques for re-establishment of dead wood for saproxylic fauna conservation. Life Nature Project NAT/IT/99/ 6245 "Bosco della Fontana" (Mantova, Italy). Gianluigi Arcari Editore, Mantova, Italy, pp. 112.

Charter M, Izhaki I, Leshem Y (2010). Effects of the risk of competition and predation on large secondary cavity breeders. Journal of Ornithology 151: 791-795. - doi: 10.1007/s10336-010-051 4-z

Charter M, Leshem Y, Izhaki I (2013). Asymmetric seasonal nest site competition between great tits and house sparrows. Journal of Ornithology 154: 173-181. - doi: 10.1007/s10336-012-08845

Cornelius C, Cockle K, Politi N, Berkunsky I, Sandoval L, Ojeda V, Rivera L, Hunter M, Martin $\mathrm{K}$ (2008). Cavity-nesting birds in neotropical forests: cavities as a potentially limiting resource. Ornitologia Neotropical 19: 253-268. [online] URL: http://www.researchgate.net/publication/230562349.pdf

Dalponte M, Gianelle D, Bruzzone L (2007). Use of hyperspectral and lidar data for classification of complex forest areas. In: "Canopy analysis and dynamics of a floodplain forest" (Gianelle
D, Travaglini D, Mason F, Minari E, Chirici G, Chemini C eds). Cierre Grafica Editore, Verona, Italy, pp. 25-37.

Dhondt AA (2012). Interspecific competition in birds. Oxford University Press, New York, USA, pp. 282. [online] URL: http://books.google.com/ books?id=Bgan-H5k70YC

Garcia-Navas V, Arroyo L, Sanz JJ, Diaz M (2008). Effect of nestbox type on occupancy and breeding biology of tree sparrows passer montanus in Central Spain. Ibis 150: 356-364. - doi: 10.1111/j.1474-919X.2008.00799.x

Gibbons P, Lindenmayer DB (2002). Tree hollows and wildlife conservation in Australia. CSIRO, Collingwood, Australia, pp. 211. [online] URL: http://books.google.com/books?id=6Q28RIlsW_I

Gotelli NJ, Entsminger GL (2001). Ecosim: null models software for ecology. Web site. [online] URL: http://www.uvm.edu/ ngotelli/EcoSim/Ec oSim.html

Larrieu L, Cabanettes A, Delarue A (2012). Impact of silviculture on dead wood and on the distribution and frequency of tree microhabitats in montane beech-fir forests of the Pyrenees. European Journal of Forest Research 131: 773-786. doi: 10.1007/s10342-011-0551-z

Levers C, Verkerk PJ, Müller D, Verburg PH, Butsic V, Leitão PJ, Lindner M, Kuemmerle T (2014). Drivers of forest harvesting intensity patterns in Europe. Forest Ecology and Management 315: 160-172. - doi: 10.1016/j.foreco.2013. 12.030

Lindenmayer DB, Welsh A, Donnelly C, Crane M, Michael D, Macgregor C, McBurney L, Montague-Drake R, Gibbons P (2009). Are nest boxes a viable alternative source of cavities for hollow-dependent animals? Long-term monitoring of nest box occupancy, pest use and attrition. Biological Conservation 142: 33-42. - doi: 10.1016/j.biocon.2008.09.026

Longo L (2001). Uccelli [Birds]. In: "Vertebrati di un bosco planiziario padano Bosco della Fontana" (Longo L, Nadali A eds). Gianluigi Arcari Editore, Mantova, Italy, pp. 21-63. [in Italian]

Longo L (2003a). Habitat trees: instructions for creating and monitoring nest holes. In: "Techniques for reestablishment of dead wood for saproxylic fauna conservation" (Cavalli R, Mason $F$ eds). Life nature project NAT/IT/99/6245 "Bosco della Fontana" (Mantova, Italy). Gianluigi Arcari Editore, Mantova, Italy, pp. 63-68.

Longo L (2003b). "Habitat trees" and other actions for birds. In: Proceedings of the International Symposium "Dead wood: a key to biodiversity" (Mason F, Nardi G, Tisato M eds). Mantova (Italy) 29-31 May 2003. Sherwood, Arezzo, Italy, pp. 49-50

Loukola OJ, Seppänen JT, Forsman JT (2012). Intraspecific social information use in the selection of nest site characteristics. Animal Behaviour 83: 629-633. - doi: 10.1016/j.anbehav.2011.12.004 Maffezzoli M, Martignoni C (2010). Report: relazione ornitologica SIC e ZPS "Bosco Fontana". Indagine conoscitiva di aggiornamento sugli uc- celli a fini gestionali [Report on the bird fauna. Study on the birds for management purposes]. In: "Integrazione del Piano di Gestione della Riserva Naturale Statale e Sito Natura 2000 IT 20B0011 Bosco della Fontana" (Hardersen S, Toni I eds). Programma di Sviluppo Rurale 2007-2013 (FEARS), Regione Lombardia, Azione 323 A, Mantova, Italy, pp. 168. [in Italian] Manning AD, Gibbons P, Fischer J, Oliver DL , Lindenmayer DB (2013). Hollow futures? Tree decline, lag effects and hollow-dependent species. Animal Conservation 16: 395-403. - doi: 10.1111/acv.12006

Martin K, Aitken KEH, Wiebe KL (2004). Nest sites and nest webs for cavity-nesting communities in interior British Columbia, Canada: nest characteristics and niche partitioning. The condor 106: 5-19. - doi: 10.1650/7482

Mason F (2004). Dinamica di una foresta della pianura padana: Bosco della fontana [Dynamic of a forest in the Po floodplain: Bosco Fontana] $\left(2^{\text {nd }}\right.$ edn). Gianluigi Arcari Editore, Mantova, Italy, pp. 224. [in Italian]

MCPFE (2007). State of Europe's forests 2007. The MCPFE report on sustainable forest management in Europe. In: " $5^{\text {th }}$ Ministerial Conference on the Protection of Forests in Europe" (MCPFE Liaison Unit Warsaw). UNECE and FAO, Warsaw, Poland, pp. 247.

Müller J, Jarzabek-Müller A, Bussler H, Gossner M (2013). Hollow beech trees identified as keystone structures for saproxylic beetles by analyses of functional and phylogenetic diversity. Animal Conservation 17 (2): 154-162. - doi: 10.11 11/acv. 12075

Newton I (1994). The role of nest sites in limiting the numbers of hole-nesting birds: a review. Biological Conservation 70: 265-276. - doi: 10.10 16/0006-3207(94)90172-4

Remm J, Lõhmus A, Remm K (2006). Tree cavities in riverine forests: what determines their occurrence and use by hole-nesting passerines? Forest Ecology and Management 221: 267-277. doi: 10.1016/j.foreco.2005.10.015

Robles H, Ciudad C, Matthysen E (2011). Treecavity occurrence, cavity occupation and reproductive performance of secondary cavity-nesting birds in oak forests: the role of traditional management practices. Forest Ecology and Management 261: 1428-1435. - doi: 10.1016/j.foreco.20 11.01.029

Robles H, Ciudad C, Matthysen E (2012). Responses to experimental reduction and increase of cavities by a secondary cavity-nesting bird community in cavity-rich pyrenean oak forests. Forest Ecology and Management 277: 46-53. doi: 10.1016/j.foreco.2012.04.017

Sebek P, Altman J, Platek M, Cizek L (2013). Is active management the key to the conservation of saproxylic biodiversity? Pollarding promotes the formation of tree hollows. PLoS ONE 8 (3): e60456. - doi: 10.1371/journal.pone. 0060456

Speight MCD (1989). Saproxylic invertebrates and their conservation. Nature and environment series, No. 42. Council of Europe, Strasbourg, France, pp. 80. 
Takeno K (2012). Stress-induced flowering. In: "Abiotic stess responses in plants. Metabolism, productivity and sustainability" (Ahmad P, Prasad MNV eds). Springer, New York, USA, pp. 331-346. - doi: 10.1007/978-1-4614-0634-1_17 Tomé R, Catry P, Bloise C, Korpimaki E (2008). Breeding density and success, and diet composition of little owls Athene noctua in steppe-like habitats in Portugal. Ornis Fennica 85: 22.
Travaglini D, Bottalico F, Brundu P, Chirici G, Minari E (2007). Sampling deadwood within Bosco della Fontana. In: "Canopy analysis and dynamics of a floodplain forest" (Gianelle D, Travaglini D, Mason F, Minari E, Chirici G, Chemini C eds). Cierre Grafica Editore, Verona, Italy, pp. 59-68.

Wesolowski T, Czeszczewik D, Rowinski P, Walankiewicz W (2002). Nest soaking in natural holes-a serious cause of breeding failure? Ornis Fennica 79: 132-138. [online] URL: http://www ib.uph.edu.pl/private/publikosob/CDOrnFenn20 0279132138.PDF

Zingg S, Arlettaz R, Schaub M (2010). Nestbox design influences territory occupancy and reproduction in a declining, secondary cavity-breeding bird. Ardea 98: 67-75. - doi: 10.5253/ 078.098.0109 